\title{
Augmented Reality, Virtual Reality and Mixed Reality in Medical Education: A Comparative Web of Science Scoping Review
}

\author{
Muhammad Fadzil Bin Kamarudin ${ }^{1 *}$, Nabil Zary ${ }^{1}$ \\ 1. Lee Kong Chian School of Medicine, Nanyang Technological University, Singapore
}

Corresponding author:

Muhammad Fadzil Bin Kamarudin

Lee Kong Chian School of Medicine, Nanyang Technological University

Email: muhammad292@e.ntu.edu.sg

\begin{abstract}
Background: Since the advent of virtual reality (VR), it has been used in medical education for surgical training and anatomy teaching. Recently, other modalities of extended reality (XR) such as augmented reality (AR) and mixed reality (MR) has also made its way into medical education. Although there has been research validating XR's use in medical education, there have been few studies on the research trends of the different XR modalities. The paper aims to compare the research trends of the XR modalities in general and in terms of the medical fields studied and outcomes measured.
\end{abstract}

Methods: Web of Science was searched, and preliminary data was extracted to analyze the general trend. Inclusion and exclusion criteria were then applied, and finalized articles were analyzed and grouped based on the medical field studied and outcomes measured.

Results: 31 articles on VR, eight on AR and one on MR were included in the final analysis. We found that there is increasing research in VR since 1990 and AR since 2008. The research in MR is constant. Most of the papers on VR studied endoscopic surgery and anatomy whereas AR studied mostly anatomy and endovascular procedures. Using Miller's prism of clinical competence, the competency measured most for VR and AR is "show".

Discussion and conclusion: Advancement in computing, communication and display technologies since 1990 may contribute to the increase in research on VR whereas the ubiquity of smartphone since 2008 may explain the increase in research on AR. Although both VR and AR are used in surgical training and anatomy teaching, we found possible strengths of VR in counseling and AR in practical skills. The competency "show" was measured most as most of the papers were on surgery, and the XR simulators used can capture surgical parameters 


\section{Introduction}

Extended reality (XR) can be conceptualized in the form of the reality-virtuality continuum (1) where on one end, there is the real world and on the other end, the virtual world, with a couple of intermediaries in between such as augmented reality (AR) and mixed reality (MR) (Figure 1).

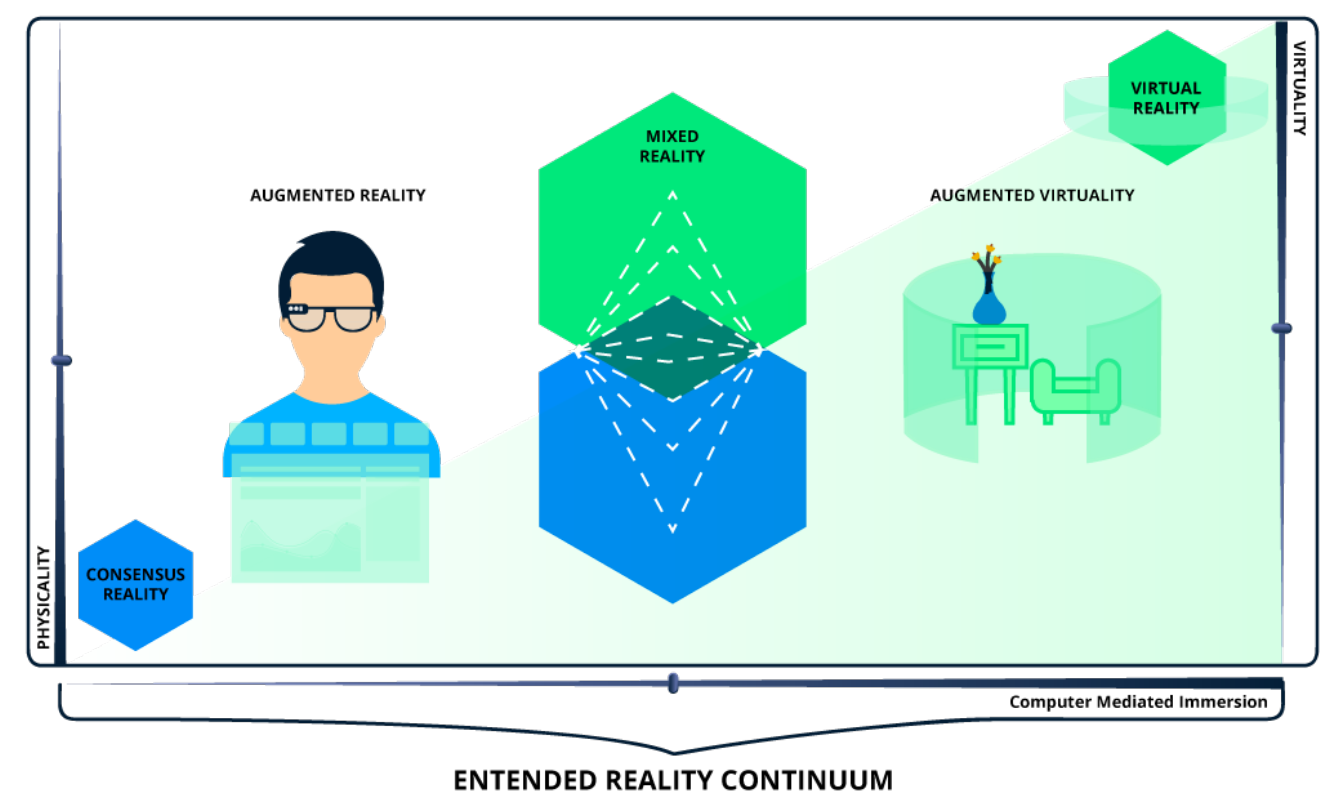

Figure 1: Overview of the Extended Reality Continuum (2)

There have been reviews studying the effectiveness of virtual reality (VR) and AR simulations in surgical training (3) (4). It has the potential to improve patient safety and reduce training times (5). $\mathrm{XR}$ has also been used in training skills such as physical exams and intravenous injections $(6,7)$. Studies have also shown that XR can complement traditional anatomy teaching (8).

However, to our knowledge, there is little research comparing the research trends of the modalities of $\mathrm{XR}$. We believe that this can give us insight into where this fast-growing field is heading towards and the factors driving the research.

Thus, this study aims to compare the research trends of the modalities of XR in general and in terms of the medical fields studied and outcomes measured.

We hypothesize that the number of papers published per year as well as the dominant medical education field studied for each modality will correlate to the modality's prevalence in medical education. We have two research questions- firstly, what are the research trends of each modality and secondly, what is the dominant medical education field studied and what are the outcomes measured for each modality?

\section{Methods}

We did a literature search on 30 Aug 2018 for articles and proceeding papers on the use of XR in medical education through Web of Science Core Collection, which includes the world's top journals from 1990 to 2018 . 
The terms used in the field of XR are often used interchangeably. For this study, we define the terms as follows (1): XR is a superset that includes the entire reality-virtuality continuum. VR is a fully digitalized environment. In AR, the central experience is the real world, supplemented by superimposed digital information. In MR, real and virtual worlds are intertwined, and users can interact with both real and virtual objects. In augmented virtuality (AVR), the central experience is the virtual world, supplemented by information from real-world objects.

We define medical education as the teaching, training, and testing of knowledge and skills used by medical students and doctors.

Four searches were done using the following key terms. To search for the literature on VR, we did a title search for ("virtual reality") AND a topic search for ("medical education"). For that of AR, we did a title search for ("augmented reality") AND a topic search for ("medical education"). For that of MR, we did a title search for ("mixed reality") AND a topic search for ("medical education"). For that of AVR, we did a title search for ("augmented virtuality") AND a topic search for ("medical education").

Data were collected from Web of Science analytics to answer our first research question on the general trend in research. This was done before applying our inclusion and exclusion criteria.

To answer our second research question, we screened the title, abstract and full text of each paper. Our inclusion criteria are that the focus of the study must be on XR, used in the context of medical education, with an outcome measured. Studies that only measured participants' perception of the technology were excluded. Skills that overlap with other professions such as nursing, for example, intravenous injection were included. However, all studies on veterinary medicine and dentistry were excluded to keep the focus on medicine. Systematic reviews were excluded. Descriptive papers were excluded as they are mostly on developing technologies.

The papers were then grouped according to the medical education field studied as well as the outcomes measured. A taxonomy based on MeSH (Medical Subject Headings) terms was created to group the papers according to the medical education field studied. To group the papers according to the outcomes measured, we used Miller's pyramid of clinical competence (9).

\section{Results}

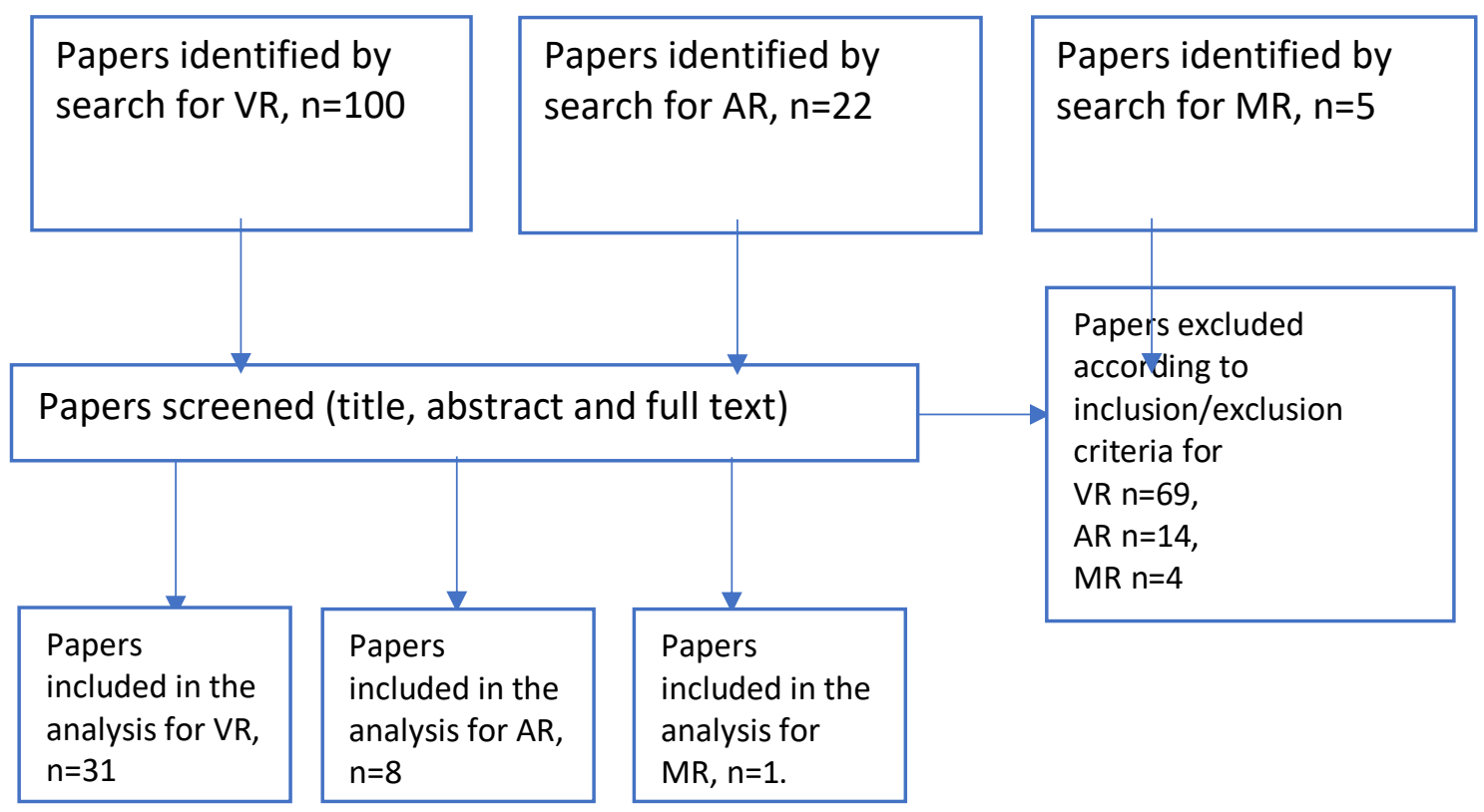


Figure 2: Publications screening process

The search generated 100 documents for VR, 22 for AR, 5 for MR and 0 for AVR.

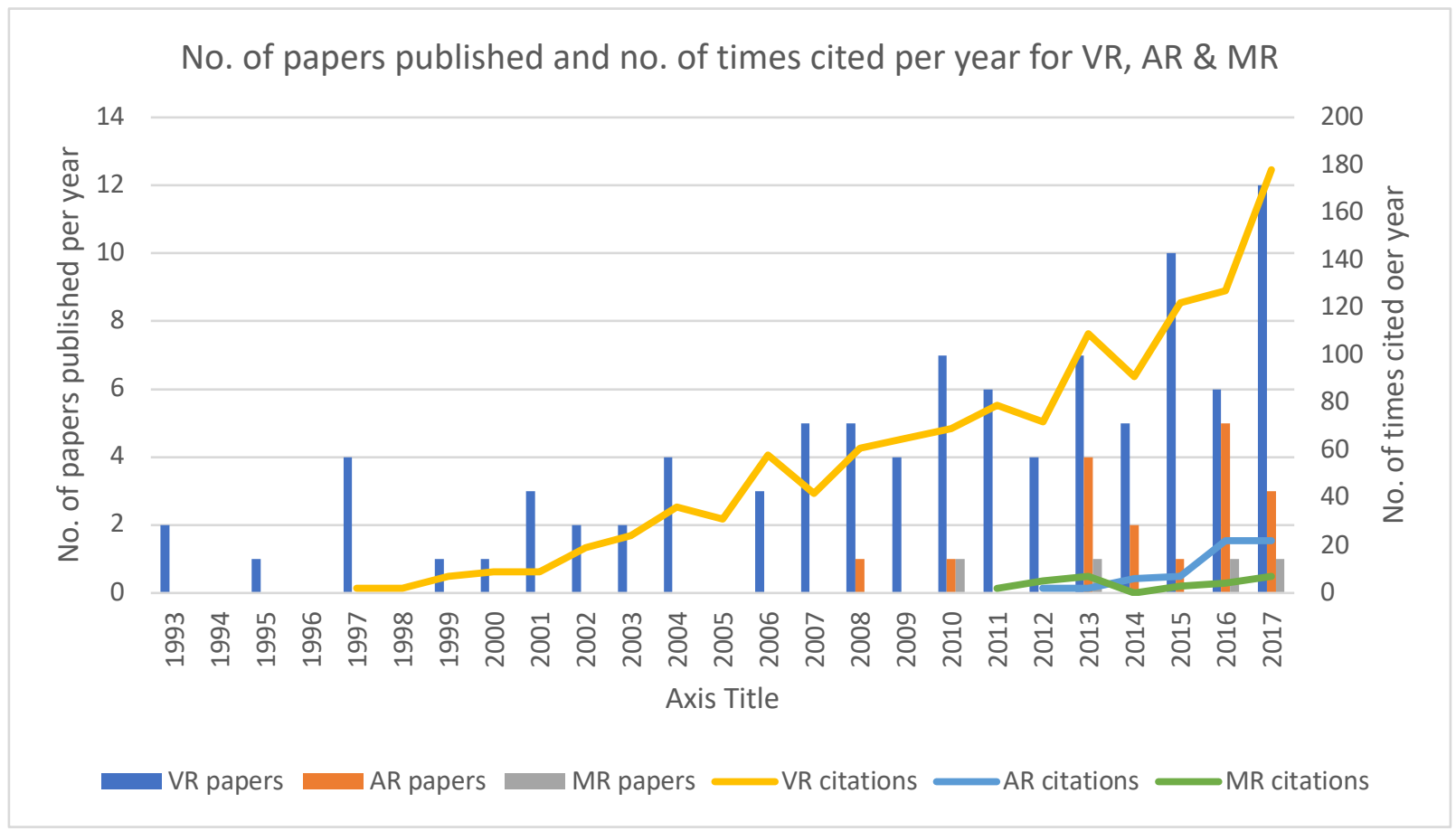

Figure 3: No. of papers published and no. of times cited per year for VR, AR \& MR

There is an increase in the number of papers published and the number of citations per year for VR since 1993. The general trend for the number of papers published for AR is also increasing since 2008. The number of papers published for MR, which first appeared in 2010, is however constant. Since 1993, the most significant number of research is in VR followed by AR and MR.

After screening the title, abstract and full text using our inclusion and exclusion criteria, 31 articles on $\operatorname{VR}(6,7,10-38)$, eight on $\operatorname{AR}(8,39-45)$ and one on MR (46) were left for analysis. 


\section{Medical Education Field Studied for VR, AR, MR}

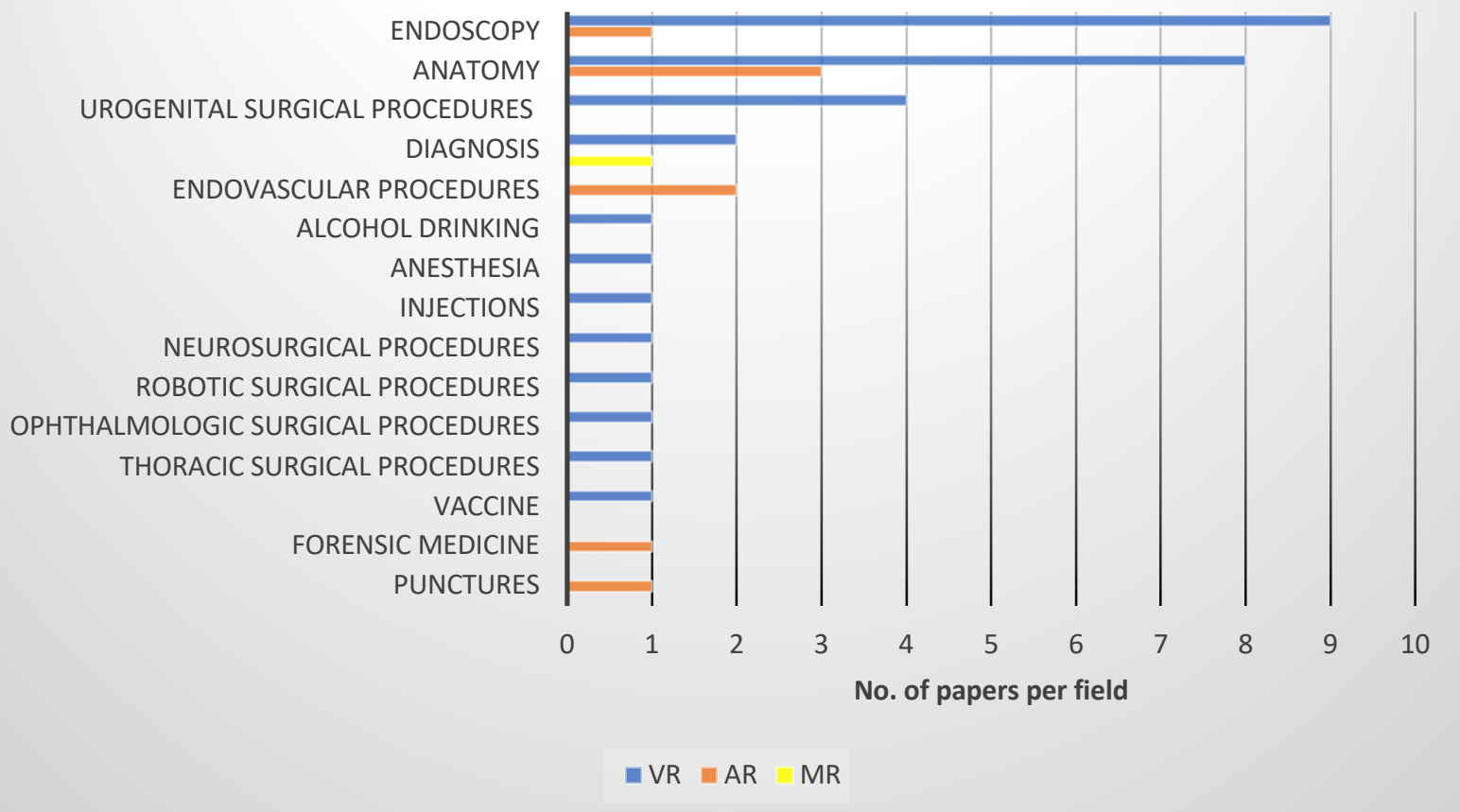

Figure 4: Medical Education Field Studied for VR, AR, MR

The field with the highest number of papers for VR is endoscopy followed by anatomy and urogenital surgery whereas that of AR is anatomy, followed by endovascular procedures. The only paper on MR was on the diagnosis.

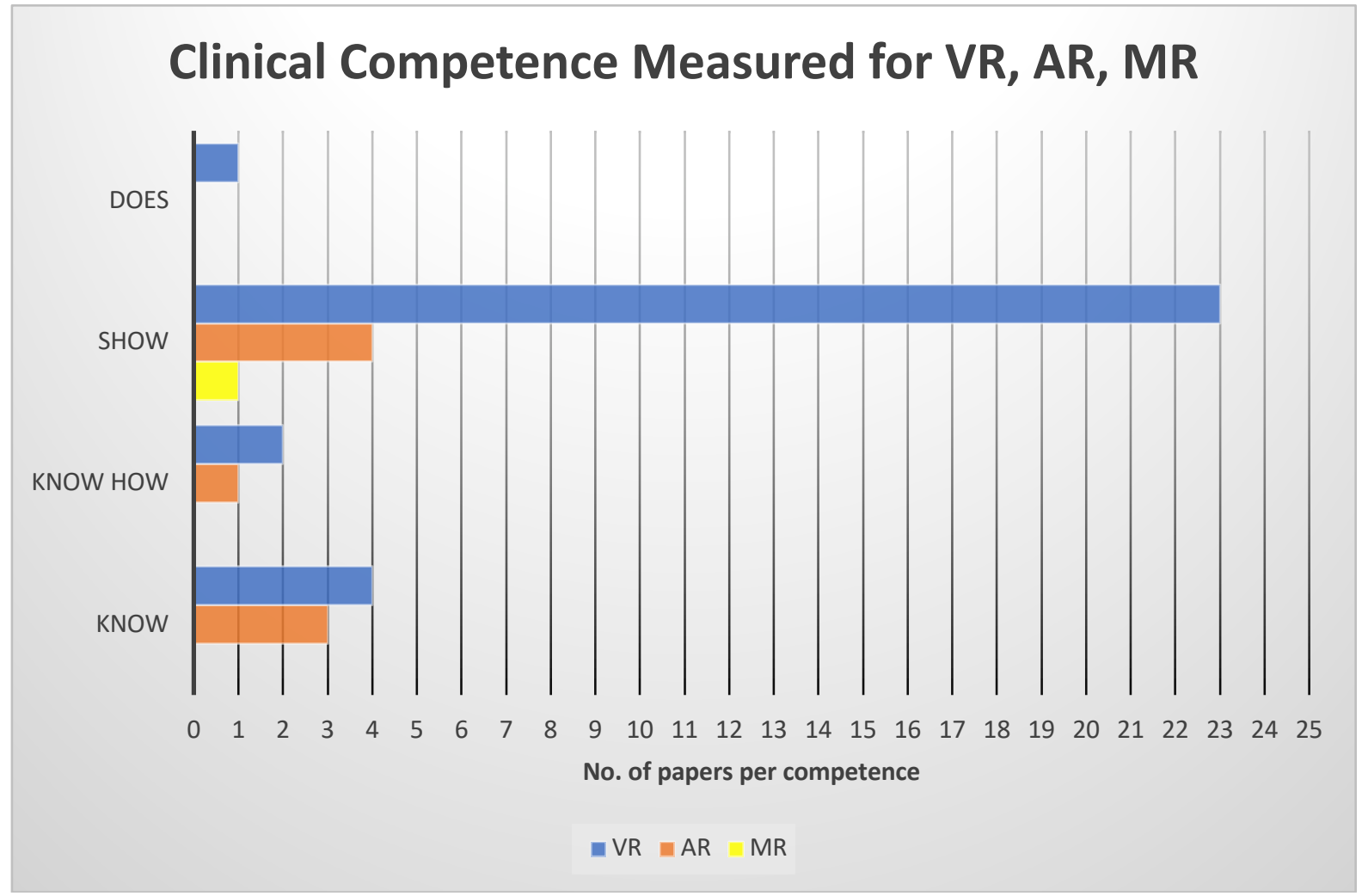

Figure 5: Clinical Competence Measured for VR, AR, MR based on Miller's Prism 
For VR and AR, most of the papers measured the competence "show", followed by "know" and "know-how". The only paper on MR measured "show". There is only one paper that measures "does", which is on VR.

\section{Discussion}

\section{General Trend}

The amount of research in a modality generally follows its prevalence in medical education, as research is needed to validate their effectiveness. VR is generally considered to be the first modality to be developed followed by AR and subsequently MR which requires more advanced technology (47). Therefore, their appearance in research follows the same pattern as the first research on VR from our study was in 1993 whereas that of AR was in 2008 and MR in 2010.

The increase in research on VR since 1993 may be due to the increasing computational power following Moore's law, which states that computing power doubles every 24 months (48). In the 1990 s, computer chips became more powerful, compact and affordable which allowed the simulation of more realistic virtual images, pushing the adoption of VR in medical education (49). Other factors include the advancement of communication and display technologies that improved latency and immersion.

The increase in research on AR since 2008 in our study can be attributed to the advent of smartphones (50). Although AR technology has been around since the 1990s such as Virtual Fixtures (51), it is only since 2008 with the introduction of smartphones that the platform for AR, which requires a processor, camera and sensors (52) is made available for the masses. With the introduction of tablets such as the iPad and Google Glasses, the research in AR is ever increasing.

In our study, research on MR appeared in 2010 and has remained constant. Microsoft Hololens introduced in 2016 can be considered one of the first commercially available MR platforms. Since we used Web of Science for our literature search, it limited our search to only the world's top publications. Since MR is still in its developmental stages, much of the papers on it may be descriptive and may not have ended up in top publications.

No papers were found for AVR as it is a new and rarely used term and is in between more popular terms such as VR and MR (1). Technologies that may be classified under AVR may be classified under VR or MR instead.

\section{Endoscopic Surgery- VR vs. AR}

Most of the papers on endoscopic surgery used semi-immersive VR surgical simulators. There is only one paper which used AR where a virtual trajectory was overlaid on a screen for trainees to trace using forceps (44). This may be due to the prevalence of VR surgical simulators such as LapSim in surgical training as they have been around longer. VR surgical simulators such as MIST VR and LapSim were introduced in 1997 (53) and 2001 respectively whereas AR surgical simulator such as ProMIS was only first studied in 2005 (54). Endoscopic surgery comprises of procedures such as endoscopy, laparoscopy and urethroscopy. Since VR simulators are completely virtual compared to AR simulators which overlay virtual information over box trainers or mannequins (55), VR simulators may be more versatile and may be able to simulate a more diverse range of surgical procedures (44). This may lead to more VR simulators being used leading to more research compared to AR simulators.

\section{Unique Uses of VR and AR}

In our study, only VR is used in the field of "alcohol" and "vaccines". These studies used virtual patients to train participants on alcohol and vaccines counseling. The strength of VR over the other modalities is that it is completely virtual and thus, allows for the creation of virtual patients for communication skills training $(33,37)$. Only AR is used in the field "puncture". The study used AR to 
overlay lasers on a model of the spine to guide lumbar puncture insertion. The strength of AR over the other modalities is that virtual markers can be superimposed over real-life mannequins and task trainers to guide procedure skills training. (56)

\section{Measured Outcomes}

George Miller introduced the prism of clinical competence which has four stages of learning (9). The stages are "know", "know-how", "show" and "does". As examples, multiple-choice questions (MCQs) are used to test learners in the "know" stage, open-ended questions in "know-how" and simulations in "show". In the "does" stage, learners are evaluated when working in clinical practice. Since the field which was researched the most for VR and AR was surgical procedures, the competence that was measured the most was "show" as the surgical simulators measured parameters such as time taken to complete a procedure. The second greatest competence measured is "know" and this is because anatomy is the second most researched field for both VR and AR. After the XR lesson on anatomy, participants were usually given MCQs to test their knowledge. The few studies that measured the competency "know-how", were on the use of VR and AR in anatomy teaching, and one of the papers measured the ability of participants to draw in missing structures (15). The only paper which measures the competency "does", was a paper on the use of VR to reduce the rates of influenza vaccine refusal (33). After counseling training through VR simulation, the rates of influenza vaccine refusal in the clinical practice of the physicians were measured. This is a rare example in our study, where results from real life practice were taken to measure the efficacy of an intervention. The only study on MR measured the competency "show" and it was on the use of MR to train pediatric developmental exams (46).

\section{Limitations}

The terms AR and MR are at times used interchangeably, and it is not always clear when deciding whether technology is strictly AR or MR. Since Web of Science is used, only publications from the top journals are found, limiting the scope of our research. The distinction between the competencies "know" and "know-how" was also at times subjective.

\section{Suggestions for Future Research}

More research can be done on the use of MR, for instance, in surgical training. Instead of just having digital markers superimposed over anatomy like in AR, giving users the ability to interact with the digital markers in real time- repositioning or changing it can further enhance training.

\section{Conclusion}

This study compared the research trends of VR, AR, and MR in medical education. We found that the amount of research for VR has been increasing since 1993 and that of AR since 2008 possibly due to improvements in computing and the advent of smartphones respectively. Research in MR appeared in 2010 and is still a developing modality. Although both VR and AR are used in surgical training and anatomy teaching, only VR via virtual patients is used to practice communication skills and only the overlay technology in AR is used to practice clinical skills such as lumbar punctures. The competency that was measured the most was "show", as most of the studies were on surgery. We hope to have given insight into which fields these technologies are heading towards in medical education and the factors driving the research.

\section{References}

1. Milgram P, Takemura H, Utsumi A, Kishino F, editors. Augmented reality: A class of displays on the reality-virtuality continuum. Telemanipulator and telepresence technologies; 1995: International Society for Optics and Photonics.

2. Zary N. Overview of the Extended Reality Continuum for Immersive Learning Experiences 2018. doi:10.6084/m9.figshare.7038605.v5. 
3. Sutherland LM, Middleton PF, Anthony A, Hamdorf J, Cregan P, Scott D, et al. Surgical simulation: a systematic review. Annals of surgery. 2006;243(3):291.

4. Barsom E, Graafland M, Schijven M. Systematic review on the effectiveness of augmented reality applications in medical training. Surgical endoscopy. 2016;30(10):4174-83.

5. Iserson KV. Ethics of Virtual Reality in Medical Education and Licensure. Cambridge Quarterly of Healthcare Ethics. 2018;27(2):326-32.

6. Langrana N, Burdea G, Ladeji J, Dinsmore M. Human performance using virtual reality tumor palpation simulation. Computers \& Graphics. 1997;21(4):451-8.

7. Jung EY, Park DK, Lee YH, Jo HS, Lim YS, Park RW. Evaluation of practical exercises using an intravenous simulator incorporating virtual reality and haptics device technologies. Nurse Education Today. 2012;32(4):458-63.

8. Moro C, Stromberga Z, Raikos A, Stirling A. The Effectiveness of Virtual and Augmented Reality in Health Sciences and Medical Anatomy. Anatomical Sciences Education. 2017;10(6):54959.

9. Miller GE. The assessment of clinical skills/competence/performance. Academic medicine. 1990;65(9):S63-7.

10. Cope DH, Fenton-Lee D. Assessment of laparoscopic psychomotor skills in interns using the mist virtual reality simulator: A prerequisite for those considering surgical training? Anz Journal of Surgery. 2008;78(4):291-6.

11. Madsen ME, Konge L, Norgaard LN, Tabor A, Ringsted C, Klemmensen AK, et al. Assessment of performance measures and learning curves for use of a virtual-reality ultrasound simulator in transvaginal ultrasound examination. Ultrasound in Obstetrics \& Gynecology. 2014;44(6):693-9.

12. Seixas-Mikelus SA, Adal A, Kesavadas T, Baheti A, Srimathveeravalli G, Hussain A, et al. Can Image-Based Virtual Reality Help Teach Anatomy? Journal of Endourology. 2010;24(4):629-34.

13. Loukas C, Nikiteas N, Kanakis M, Georgiou E. Deconstructing laparoscopic competence in a virtual reality simulation environment. Surgery. 2011;149(6):750-60.

14. Jang S, Vitale JM, Jyung RW, Black JB. Direct manipulation is better than passive viewing for learning anatomy in a three-dimensional virtual reality environment. Computers \& Education. 2017; 106:150-65.

15. Jang S, Black JB, Jyung RW. Embodied Cognition and Virtual Reality in Learning to Visualize Anatomy. Ohlsson S, Catrambone R, editors2010. 2326-31 p.

16. Fang TY, Wang PC, Liu CH, Su MC, Yeh SC. Evaluation of a haptics-based virtual reality temporal bone simulator for anatomy and surgery training. Computer Methods and Programs in Biomedicine. 2014;113(2):674-81.

17. Sweet R, Kowalewski T, Oppenheimer P, Weghorst S, Satava R. Face, content and construct validity of the University of Washington virtual reality transurethral prostate resection trainer. Journal of Urology. 2004;172(5):1953-7.

18. Kulcsar Z, O'Mahony E, Lovquist E, Aboulafia A, Sabova D, Ghori K, et al. Preliminary evaluation of a virtual reality-based simulator for learning spinal anesthesia. Journal of Clinical Anesthesia. 2013;25(2):98-105.

19. AlZhrani G, Alotaibi F, Azarnoush H, Winkler-Schwartz A, Sabbagh A, Bajunaid K, et al. Proficiency Performance Benchmarks for Removal of Simulated Brain Tumors Using a Virtual Reality Simulator NeuroTouch. Journal of Surgical Education. 2015;72(4):685-96.

20. Hashimoto DA, Petrusa E, Phitayakorn R, Valle C, Casey B, Gee D. A proficiency-based virtual reality endoscopy curriculum improves performance on the fundamentals of endoscopic surgery examination. Surgical Endoscopy and Other Interventional Techniques. 2018;32(3):1397-404. 21. Kockro RA, Amaxopoulou C, Killeen T, Wagner W, Reisch R, Schwandt E, et al. Stereoscopic neuroanatomy lectures using a three-dimensional virtual reality environment. Annals of Anatomy-Anatomischer Anzeiger. 2015;201:91-8.

22. Jacomides L, Ogan K, Cadeddu JA, Pearle MS. Use of a virtual reality simulator for ureteroscopy training. Journal of Urology. 2004;171(1):320-3.

23. Sikder S, Luo J, Banerjee PP, Luciano C, Kania P, Song JC, et al. The use of a virtual reality surgical simulator for cataract surgical skill assessment with 6 months of intervening operating room experience. Clinical Ophthalmology. 2015;9:141-9. 
24. Jensen K, Bjerrum F, Hansen HJ, Petersen RH, Pedersen JH, Konge L. Using virtual reality simulation to assess competence in video-assisted thoracoscopic surgery (VATS) lobectomy. Surgical Endoscopy and Other Interventional Techniques. 2017;31(6):2520-8.

25. Strom P, Kjellin A, Hedman L, Johnson E, Wredmark T, Fellader-Tsai L. Validation and learning in the procedicus KSA virtual reality surgical simulator - Implementing a new safety culture in medical school. Surgical Endoscopy and Other Interventional Techniques. 2003;17(2):227-31.

26. Harrison P, Raison N, Abe T, Watkinson W, Dar F, Challacombe B, et al. The Validation of a Novel Robot-Assisted Radical Prostatectomy Virtual Reality Module. Journal of Surgical Education. 2018;75(3):758-66.

27. Davoudi M, Osann K, Colt HG. Validation of two instruments to assess technical bronchoscopic skill using virtual reality simulation. Respiration. 2008;76(1):92-101.

28. de Faria JWV, Teixeira MJ, Sousa LD, Otoch JP, Figueiredo EG. Virtual and stereoscopic anatomy: when virtual reality meets medical education. Journal of Neurosurgery. 2016;125(5):110511.

29. Codd AM, Choudhury B. Virtual Reality Anatomy: Is it Comparable with Traditional Methods in the Teaching of Human Forearm Musculoskeletal Anatomy? Anatomical Sciences Education. 2011;4(3):119-25.

30. Levinson AJ, Weaver B, Garside S, McGinn H, Norman GR. Virtual reality and brain anatomy: a randomised trial of e-learning instructional designs. Medical Education. 2007;41(5):495501.

31. Colt HG, Crawford SW, Galbraith O. Virtual reality bronchoscopy simulation - A revolution in procedural training. Chest. 2001;120(4):1333-9.

32. Banaszek D, You D, Chang J, Pickell M, Hesse D, Hopman WM, et al. Virtual Reality Compared with Bench-Top Simulation in the Acquisition of Arthroscopic Skill A Randomized Controlled Trial. Journal of Bone and Joint Surgery-American Volume. 2017;99(7).

33. Real FJ, DeBlasio D, Beck AF, Ollberding NJ, Davis D, Cruse B, et al. A Virtual Reality Curriculum for Pediatric Residents Decreases Rates of Influenza Vaccine Refusal. Academic Pediatrics. 2017;17(4):431-5.

34. Kiely DJ, Gotlieb WH, Lau S, Zeng X, Samouelian V, Ramanakumar AV, et al. Virtual reality robotic surgery simulation curriculum to teach robotic suturing: a randomized controlled trial. Journal of Robotic Surgery. 2015;9(3):179-86.

35. Angulo JC, Arance I, Garcia-Tello A, Heras MML, Andres G, Gimbernat H, et al. Virtual reality simulator for training on photoselective vaporization of the prostate with $980 \mathrm{~nm}$ diode laser and learning curve of the technique. Actas Urologicas Espanolas. 2014;38(7):451-8.

36. Zhu H, Zhang Y, Liu JS, Wang G, Yu CF, Na YQ. Virtual reality simulator for training urologists on transurethral prostatectomy. Chinese Medical Journal. 2013;126(7):1220-3.

37. Fleming M, Olsen D, Stathes H, Boteler L, Grossberg P, Pfeifer J, et al. Virtual Reality Skills Training for Health Care Professionals in Alcohol Screening and Brief Intervention. Journal of the American Board of Family Medicine. 2009;22(4):387-98.

38. Nickel F, Brzoska JA, Gondan M, Rangnick HM, Chu J, Kenngott HG, et al. Virtual Reality Training Versus Blended Learning of Laparoscopic Cholecystectomy A Randomized Controlled Trial With Laparoscopic Novices. Medicine. 2015;94(20).

39. Yeo CT, Ungi T, Leung R, Moult E, Sargent D, McGraw R, et al. Augmented reality assistance in training needle insertions of different levels of difficulty. In: Fei B, Webster RJ, editors. Medical Imaging 2018: Image-Guided Procedures, Robotic Interventions, and Modeling. Progress in Biomedical Optics and Imaging. 105762018.

40. Albrecht UV, Folta-Schoofs K, Behrends M, von Jan U. Effects of Mobile Augmented Reality Learning Compared to Textbook Learning on Medical Students: Randomized Controlled Pilot Study. Journal of Medical Internet Research. 2013;15(8).

41. Bork F, Barmaki R, Eck U, Yu K, Sandor C, Navab N. Empirical Study of Non-Reversing Magic Mirrors for Augmented Reality Anatomy Learning. Broll W, Regenbrecht H, Swan JE, editors2017. 169-76 p.

42. Rochlen LR, Levine R, Tait AR. First-Person Point-of-View-Augmented Reality for Central Line Insertion Training. Simulation in Healthcare-Journal of the Society for Simulation in Healthcare. 2017;12(1):57-62. 
43. Kucuk S, Kapakin S, Goktas Y. Learning Anatomy via Mobile Augmented Reality: Effects on Achievement and Cognitive Load. Anatomical Sciences Education. 2016;9(5):411-21.

44. Tokuyasu T, Okamura W, Kusano T, Inomata M, Shiraishi N, Kitanou S, editors. Training system for endoscopic surgery by using augmented reality and forceps control devices. Broadband and Wireless Computing, Communication and Applications (BWCCA), 2014 Ninth International Conference on; 2014: IEEE.

45. Huang CY, Thomas JB, Alismail A, Cohen A, Almutairi W, Daher NS, et al. The use of augmented reality glasses in central line simulation: "see one, simulate many, do one competently, and teach everyone". Advances in Medical Education and Practice. 2018;9:357-63.

46. Chuah JH, Lok B, Black E. Applying mixed reality to simulate vulnerable populations for practicing clinical communication skills. IEEE transactions on visualization and computer graphics. 2013;19(4):539-46.

47. Mazuryk T, Gervautz M. Virtual reality-history, applications, technology and future. 1996.

48. Krummel TM. Surgical simulation and virtual reality: the coming revolution. Annals of surgery. 1998;228(5):635.

49. Hamacher A, Kim SJ, Cho ST, Pardeshi S, Lee SH, Eun S-J, et al. Application of virtual, augmented, and mixed reality to urology. International neurourology journal. 2016;20(3):172.

50. Yuen SC-Y, Yaoyuneyong G, Johnson E. Augmented reality: An overview and five directions for AR in education. Journal of Educational Technology Development and Exchange (JETDE). 2011;4(1):11.

51. Rosenberg LB. The Use of Virtual Fixtures as Perceptual Overlays to Enhance Operator Performance in Remote Environments. Stanford Univ Ca Center for Design Research; 1992.

52. Kamphuis C, Barsom E, Schijven M, Christoph N. Augmented reality in medical education? Perspectives on medical education. 2014;3(4):300-11.

53. Wilson M, Middlebrook A, Sutton C, Stone R, McCloy R. MIST VR: a virtual reality trainer for laparoscopic surgery assesses performance. Annals of the Royal College of Surgeons of England. 1997;79(6):403.

54. Lahanas V, Georgiou E, Loukas C. Surgical simulation training systems: box trainers, virtual reality and augmented reality simulators. Int J Adv Robot Automn. 2016;1:1-9.

55. Botden S, Berlage J, Schijven MP, Jakimowicz JJ. Face validity study of the ProMIS augmented reality laparoscopic suturing simulator. Surg Technol Int. 2008;17:26-32.

56. Yeo CT, Ungi T, Leung R, Moult E, Sargent D, McGraw R, et al., editors. Augmented reality assistance in training needle insertions of different levels of difficulty. Medical Imaging 2018: ImageGuided Procedures, Robotic Interventions, and Modeling; 2018: International Society for Optics and Photonics. 